\title{
Upper Gastrointestinal Symptoms in General Population of a District in Bangladesh
}

\author{
Irin Perveen ${ }^{1}$, Mufti Munsurar Rahman ${ }^{2}$, Madhusudan Saha ${ }^{3}$ \\ Received: June 12, 2013 Accepted: January 12, 2014
}

\begin{abstract}
Background: Upper gastrointestinal (GI) symptoms are common complaints affecting 25-40\% of the general population and are common causes of health care utilisation and substantially affect the quality of life. In day-to-day practice our clinicians have to face good number of patients with various upper GI symptoms. But we have limited data on the prevalence of different upper GI symptoms in our community. Objective: The present study aimed to find out the prevalence of different upper GI symptoms in the general population of a district in Bangladesh. Materials and Methods: This population-based observational study was conducted in a selected district of Bangladesh. Three thousand subjects selected by cluster sampling method were interviewed by a valid bowel disease questionnaire. Student's t test and chi-square tests were used for comparison of different variables with significance level set at 0.05. Results: Among the study population 1523 were men and 1477 were women with a mean age of $33.91 \pm 16.43$ years. A total of 2273 (75.8\%) persons had at least one upper GI symptom, 2072 (69.1\%) had 2 or more symptoms and 1705 (56.8\%) had 3 or more symptoms in the prior 3 months. Nine hundred sixty three subjects (32.1\%) had upper abdominal pain, 1265 (42.16\%) had bloating, 1354 (45.13\%) had heart-burn, 1166 (38.87\%) had chest pain, 1347 (44.9\%) had early satiation and 258 (8.6\%) had vomiting. Around 249 (8.3\%, male 123, female 126, $P=0.691)$ was diagnosed as functional dyspepsia, 187 (6.2\%, male 82, female 105, $P=0.059)$ as gastroesophageal reflux disease (GERD) and 55 (1.83\%, male 27, female 28, $P=0.892)$ as upper abdominal bloating. Only one woman fulfilled the criteria for functional gallbladder or sphincter of Oddi dysfunction. Approximately 40.56\% dyspeptic patients had overlapping GERD symptoms. Symptom prevalence was found to decrease with increased number, frequency and duration of symptoms. Conclusion: Upper GI symptoms are prevalent in our community. Multiple upper GI symptoms do exist simultaneously. Symptom prevalence varies with number, frequency and duration of symptoms.
\end{abstract}

Key words: Upper gastrointestinal symptoms; Functional dyspepsia; GERD; General population

J Enam Med Col 2014; 4(2): 79-88

\section{Introduction}

Upper gastrointestinal (GI) symptoms refer to a wide range of symptoms including dyspeptic symptoms as well as gastro-oesophageal reflux symptoms. ${ }^{1}$ These are the common complaints affecting $25-40 \%$ of the general population during their lifetime. ${ }^{2,3}$ In a systematic review Heading ${ }^{4}$ reported that prevalence of upper abdominal pain or discomfort ranged from $8-54 \%$, while that of heart-burn ranged from $10-48 \%$, for regurgitation from $9-45 \%$ and for both/either 21-59\%. Prevalence of upper GI symptoms varies with definition used, population involved (national vs. regional, Asian vs. Western), recall period, sex

1. Associate Professor, Department of Gastroenterology, Enam Medical College \& Hospital, Savar, Dhaka

2. Professor, Department of Medicine, Enam Medical College \& Hospital, Savar, Dhaka

3. Associate Professor, Department of Gastroenterology, North East Medical College \& Hospital, Sylhet

Correspondence Irin Perveen, Email: irinperveen@yahoo.com 
and age. ${ }^{5}$ Upper GI symptoms are a common cause of health care utilisation ${ }^{6-9}$ and substantially affect the quality of life and psychological well-being of those affected.

The pathophysiology of upper GI symptoms is still poorly understood. Organic disorders only account for a minority of cases. ${ }^{5}$ Many organic and metabolic disorders like peptic ulcer disease (PUD), cancer of GI and biliary tract, chronic pancreatitis, thyroid hormone disorder, chronic renal disease, and medications produce dyspeptic symptoms. ${ }^{10}$ Majority of the patients with upper GI symptoms belong to functional GI disorder (FGID) (62-79.5\%). ${ }^{2,3,11-13}$ Visceral hypersensitivity, delayed gastric emptying and altered brain-gut interactions have been postulated as underlying mechanisms for FGIDs. ${ }^{14,15}$ A subset of patients with ulcer-like symptoms, reflux like dyspepsia and patients with post-prandial pain were found to improve by proton pump inhibitors. ${ }^{16-18}$ These findings suggest that gastric acid secretion may play a role in the pathogenesis of functional upper GI symptoms ${ }^{19,20}$, but subjective evidence of increased gastric acid output is lacking. Psychological symptoms of neurosis, anxiety, hypochondriasis and depression $^{21}$ were found to be more common in patients with functional gastrointestinal complaints, but it is debated whether they are primarily linked to GI symptoms or rather represent motivations for health-care seeking.

Dyspepsia refers to a symptom or a set of symptoms that is (are) considered to originate from the gastroduodenal region. According to Rome II, dyspepsia is 'pain or discomfort' centered in the upper abdomen. ${ }^{8}$ Other dyspeptic symptoms are epigastric pain, epigastric burning, postprandial fullness, early satiation, upper abdominal bloating, nausea, vomiting, belching and others. ${ }^{10}$ "Functional dyspepsia" is often used interchangeably with "dyspepsia". Functional dyspepsia (FD) is defined as a condition in which upper GI symptoms occur in the absence of organic disease that explains them. ${ }^{10}$ Prevalence of dyspepsia in the general population ranges from $20-40 \% .{ }^{4,22,23}$ Most patients with uninvestigated dyspepsia are found to have FD (i.e. no endoscopic evidence of structural abnormality). ${ }^{1}$

Besides cultural difference in reporting of symptoms of dyspepsia, dietary factors, psycho-social factors,
GI infection including Helicobacter pylori infection, organic diseases such as peptic ulcer and gastric cancer in the study population may influence the epidemiology of dyspepsia. ${ }^{1}$ In Asia most of the patients $(68 \%)$ with FD present within 6 months of symptom onset and 3 months duration is enough for considering one as a case of functional dyspepsia. ${ }^{16}$

Abnormal reflux of gastric contents to oesophagus is responsible for symptoms of gastro-oesophageal reflux disease (GERD). ${ }^{17}$ Various environmental or lifestyle risk factors like obesity, fatty food, smoking, alcohol and NSAIDS are thought to be associated with GERD. ${ }^{7,17}$ Heart-burn is the major symptom of GERD and the terminology is influenced by sociocultural factors and deficiency of appropriate terminology in some Asian countries. ${ }^{10}$ GERD has traditionally been considered less common in Asian countries in comparison to western world.7,17,18,24-29 The variable range of prevalence of heart-burn and/or regurgitation may be due to different understandings of these terms by different investigators and subjects. ${ }^{4}$

In the absence of objective evidence of oesophagitis specifically in non-erosive reflux disease ${ }^{3}$, GERD symptoms play a pivotal role in the diagnosis of the problem. Heart-burn and/or acid regurgitation are considered to be reasonably specific symptoms for the diagnosis of GERD. ${ }^{17}$ According to the recent guidelines GERD is the likely diagnosis if heart-burn is the only presenting symptom or the predominant symptom. $^{23}$

A portion of FD patients not only overlap with irritable bowel syndrome (IBS) $(14-67 \%)^{28,29}$, but also overlap with GERD. ${ }^{30,31}$ Overlapping of FD and GERD is common in patient-based series as well as in epidemiological settings (24-29.4\%). ${ }^{15,30,31}$ Researchers $^{21}$ suggested that shared, common and generalised pathophysiological disturbances of the gut are responsible for overlapping diagnoses of functional GI disorders.

Though upper GI symptoms are common in our dayto-day practice, we are lacking in data regarding the proportionate contribution of different upper GI symptoms in the disease burden. The aim of this study was to determine the prevalence of upper gastrointestinal symptoms (UGIS) in the general population of a district in Bangladesh. 


\section{Materials and Methods}

\section{Study setting}

This observational study was conducted in Sylhet district of Bangladesh during the period of August to December 2011.

\section{Subjects and survey methods}

By cluster sampling method 3000 subjects aged more than 15 years were selected. A total of ten clusters (each mahalla $=1$ cluster) from the city and ten clusters ( 1 village $=1$ cluster) from the villages were selected at random. Informed consents were taken from the participants. Subjects were interviewed in a home setting by trained data collectors under direct supervision of investigators. Subjects having major psychotic episodes, mental retardation, dementia, severe visual or hearing abnormalities, a history of abdominal or gynecological surgery, gastrointestinal cancer, ulcerative colitis, Crohn's disease, diabetes mellitus, thyroid disorder or other major organic disorders were excluded from the study.

\section{Questionnaire}

A previously validated questionnaire based on Rome III diagnostic criteria for adult functional dyspepsia and other upper GI symptoms ${ }^{32}$ was used for data collection. Bengali translation of the questionnaire was performed by the method of forward and backward translation and tested for clarity in a sample of 50 patients. This initial survey showed that the questions were easily understandable to the study population.

\section{Study definitions}

Dyspepsia was defined as recurrent or chronic pain or discomfort in the upper abdomen for $\geqslant 3$ months. It also included epigastric burning, postprandial fullness, early satiation, bloating in the upper abdomen, nausea and vomiting.

FD was defined as a condition in which upper GI symptoms occurred in the absence of structural and biochemical causes (Rome III, www.romecriteria. org.criteria). Rome III definition of FD will require the presence of 1 or more dyspepsia symptoms (bothersome postprandial fullness, early satiation, epigastric pain and epigastric burning) occurring more than a quarter of the time at least for 3 months, with onset at least six months back with no evidence of structural disease that is likely to explain the symptoms. FD patients were classified according to their symptoms as postprandial distress syndrome (PDS) alone, epigastric pain syndrome (EPS) alone or coexistence of PDS and EPS (PDS+EPS) subtypes.

GERD was defined as heart-burn occurring at least once a week in patients without dyspepsia. The following definitions were used to identify individual symptoms in the GERD questionnaire.

Heart-burn - a burning pain or discomfort in the central chest behind the sternum.

Chest pain - feeling of any pain or discomfort inside the central chest, excluding heart-burn, primary abdominal pain and past history of ischaemic cardiac pain.

Upper abdominal bloating included upper abdominal bloating, visible distension or post-prandial fullness for at least 3 days per month in the absence of functional dyspepsia, inflammatory bowel syndrome (IBS), functional constipation (FC) and other disorders with symptom onset at least 6 months prior to diagnosis (Rome III).

Functional gallbladder disorder or sphincter of Oddi dysfunction was defined according to Rome III criteria.

\section{Statistical analysis}

The data were processed, and statistical analysis was performed with a SPSS 20.0 programme (SPSS Inc., Chicago, IL, USAIBM). Student's $t$ test was used to compare the distributions of age and other continuous variables. Pearson's chi-square test was used for comparison of categorical variables such as distributions of sex, individual symptom and subtype. For all comparison significance level was set at 0.05 .

\section{Results}

Out of 2,555,000 population of Sylhet district, 1523 (50.08\%) men and $1477(49.2 \%)$ women in the age range of 15-97 years (mean \pm SD $33.91 \pm 16.43$ ) were interviewed. The mean age of the FD patients $(41.08 \pm 17.84$ years $)$ and reflux disease patients $(36.73 \pm 16.57$ years) were significantly higher than the mean age of the total study population. Table I summarises the patient characteristics of the upper GI symptoms. 
Table I: Sociodemographic characteristics of study population and subjects with FD, RD and upper abdominal bloating

\begin{tabular}{|c|c|c|c|c|}
\hline Variables & $\begin{array}{c}\text { FD } \\
\text { Number (\%) }\end{array}$ & $\begin{array}{c}\text { Reflux disease } \\
\text { Number (\%) }\end{array}$ & $\begin{array}{c}\text { Upper abdominal bloating } \\
\text { Number }(\%)\end{array}$ & $\begin{array}{c}\text { Total } \\
\text { population }\end{array}$ \\
\hline Prevalence & $249(8.3)$ & $187(6.2)$ & $55(1.83)$ & $3000(100)$ \\
\hline Mean age (years) & $41.08 \pm 17.84$ & $36.73 \pm 16.57$ & $36.53 \pm 17.03$ & $33.91 \pm 16.43$ \\
\hline \multicolumn{5}{|l|}{ Education } \\
\hline Illiterate & $121(12.98)$ & $76(8.15)$ & $25(2.7)$ & $932(31.3)$ \\
\hline Primary & $93(7.2)$ & $81(6.31)$ & $21(1.6)$ & $1283(42.8)$ \\
\hline $\mathrm{SSC}$ & $23(9.2)$ & $20(3.97)$ & $4(0.8)$ & $503(16.8)$ \\
\hline HSC & $5(2.0)$ & $7(8.3)$ & $4(2.1)$ & $188(6.3)$ \\
\hline Graduate & $7(2.8)$ & $2(2.38)$ & $1(1.2)$ & $84(2.8)$ \\
\hline Post-graduate & 0 & $1(10.0)$ & 0 & $10(0.3)$ \\
\hline $\mathrm{P}$ value & $\mathrm{P}=0.000$ & $\mathrm{P}=0.012$ & $\mathrm{P}=0.187$ & \\
\hline \multicolumn{5}{|c|}{ Economic condition } \\
\hline Poor & $81(12.96)$ & $23(3.68)$ & $9(1.4)$ & $625(20.8)$ \\
\hline Lower & $101(6.75)$ & $89(5.95)$ & $35(2.3)$ & 1497 (49.9) \\
\hline Middle & $48(7.3)$ & $40(6.06)$ & $7(1.1)$ & $660(22.0)$ \\
\hline High & $19(8.71)$ & $15(7.3)$ & $4(1.8)$ & $218(7.3)$ \\
\hline$P$ value & $\mathrm{P}=0.000$ & $\mathrm{P}=0.838$ & $\mathrm{P}=0.183$ & \\
\hline \multicolumn{5}{|l|}{ Occupation } \\
\hline Service holder & $13(7.5)$ & $14(8.1)$ & $2(1.2)$ & $173(5.8)$ \\
\hline Business & $49(10.2)$ & $22(4.56)$ & $7(1.5)$ & $482(16.1)$ \\
\hline Student & $12(4.8)$ & $11(3.1)$ & $5(1.4)$ & $355(11.8)$ \\
\hline Housewife & $99(3.4)$ & $87(7.87)$ & $21(1.9)$ & $1105(36.8)$ \\
\hline Day labourer & $18(10.97)$ & $10(6.1)$ & $4(2.4)$ & $164(5.5)$ \\
\hline Farmer & $20(10.52)$ & $13(6.84)$ & $6(3.2)$ & $190(6.3)$ \\
\hline Others & $38(7.15)$ & $20(3.77)$ & $5(1.9)$ & $531(17.7)$ \\
\hline$P$ value & $\mathrm{P}=0.006$ & $\mathrm{P}=0.022$ & $\mathrm{P}=0.756$ & \\
\hline
\end{tabular}

A total of $2273(75.8 \%$, male 1142, female 1131, $\mathrm{P}=0.327$ ) persons were identified with at least one upper GI symptom during the period of last 3 months, $2072(69.1 \%)$ had 2 or more symptoms, $1705(56.8 \%)$ had 3 or more symptoms, 1464 $(48.8 \%)$ had 4 or more symptoms and $441(14.7 \%)$ had 5 or more symptoms. At least one of the upper GI symptoms occurred monthly in 1938 subjects and weekly in 1090 subjects.

Table II shows frequency and distribution of different dyspeptic symptoms in study population. Total 963 (32.1\%, male 464, female 499, $\mathrm{P}=0.055$ ) had upper abdominal pain, 1265 (42.2\%, male 633, female 632) had upper abdominal bloating and 1347 (44.9\%, male 664, female 683) had early satiety. Approximately $27.6 \%(\mathrm{n}=828)$ had only epigastric pain occurring at any time in the last 3 months. Out of these 828 subjects, $175(21.14 \%)$ subjects were classified as FD and $20(2.42 \%)$ as functional bloating. In 289 (9.6\%) subjects with epigastric pain, pain was relieved by antacid frequently or most of the times and pain persisted for more than 1 day in $182(6.1 \%)$ subjects. Pain was relieved by antacid more in FD patients than in subjects without FD (46, $18.5 \%$ vs. $243,8.8 \%$ ). 
Table II: Frequency and distribution of different upper GI symptoms in study population

\begin{tabular}{|c|c|c|c|c|c|}
\hline Symptoms & Frequency & $\begin{array}{c}\text { Male } \\
\text { Number (\%) }\end{array}$ & $\begin{array}{c}\text { Female } \\
\text { Number (\%) }\end{array}$ & $\begin{array}{c}\text { Total } \\
\text { Number (\%) }\end{array}$ & $\mathrm{P}$ value \\
\hline Upper abdominal pain & $\begin{array}{l}<\text { Once/month } \\
\text { Monthly } \\
\text { Weekly }\end{array}$ & $\begin{array}{l}464(30.5) \\
396(26.0) \\
290(19.0)\end{array}$ & $\begin{array}{l}499(33.8) \\
434(29.4) \\
321(21.7)\end{array}$ & $\begin{array}{l}963(32.1) \\
830(27.7) \\
611(20.4)\end{array}$ & $\begin{array}{l}0.055 \\
0.041 \\
0.070\end{array}$ \\
\hline Epigastric pain & $\begin{array}{l}<\text { Once/month } \\
\text { Monthly } \\
\text { Weekly } \\
\text { Duration }>6 \text { mo }\end{array}$ & $\begin{array}{c}406(26.66) \\
314(20.62) \\
78(5.12) \\
326(21.4)\end{array}$ & $\begin{array}{c}422(28.57) \\
336(22.75) \\
96(6.5) \\
329(22.27)\end{array}$ & $\begin{array}{c}828(27.6) \\
650(21.67) \\
174(5.8) \\
655(21.83)\end{array}$ & $\begin{array}{l}0.253 \\
0.169 \\
0.118 \\
0.422\end{array}$ \\
\hline Chest pain & $\begin{array}{l}<\text { Once/month } \\
\text { Monthly } \\
\text { Weekly }\end{array}$ & $\begin{array}{c}543(35.65) \\
459(30.17) \\
102(6.68)\end{array}$ & $\begin{array}{c}623(42.18) \\
558(37.8) \\
173(11.71)\end{array}$ & $\begin{array}{c}1166(38.87) \\
1017(33.9) \\
275(9.17)\end{array}$ & $\begin{array}{l}0.000 \\
0.000 \\
0.000\end{array}$ \\
\hline Heart-burn & $\begin{array}{l}<\text { Once/month } \\
\text { Monthly } \\
\text { Weekly }\end{array}$ & $\begin{array}{c}666(43.7) \\
598(39.3) \\
120(7.9)\end{array}$ & $\begin{array}{l}689(46.6) \\
626(42.9) \\
168(11.4)\end{array}$ & $\begin{array}{c}1354(45.13) \\
1244(40.8) \\
288(9.6)\end{array}$ & $\begin{array}{l}0.115 \\
0.087 \\
0.000\end{array}$ \\
\hline $\begin{array}{l}\text { Upper abdominal } \\
\text { bloating }\end{array}$ & $\begin{array}{l}<\text { Once/month } \\
\text { Monthly } \\
\text { Weekly } \\
\text { Duration }>6 \text { mo }\end{array}$ & $\begin{array}{c}633(41.6) \\
504(33.1) \\
102(6.7) \\
09(26.85)\end{array}$ & $\begin{array}{c}632(42.8) \\
511(34.6) \\
114(7.72) \\
451(30.53)\end{array}$ & $\begin{array}{c}1265(42.2) \\
1015(33.8) \\
216(7.2) \\
860(28.67)\end{array}$ & $\begin{array}{l}0.563 \\
0.396 \\
0.290 \\
0.003\end{array}$ \\
\hline Early satiation & $\begin{array}{l}<\text { Once/month } \\
\text { Monthly } \\
\text { Weekly } \\
\text { Duration }>6 \text { mo }\end{array}$ & $\begin{array}{c}664(43.6) \\
565(37.09) \\
126(11.5) \\
468(30.72)\end{array}$ & $\begin{array}{c}683(46.24) \\
605(40.96) \\
211(14.3) \\
564(38.19)\end{array}$ & $\begin{array}{c}1347(44.9) \\
1170(39.03) \\
386(12.9) \\
1032(34.4)\end{array}$ & $\begin{array}{l}0.006 \\
0.033 \\
0.025 \\
0.000\end{array}$ \\
\hline $\begin{array}{l}\text { Vomiting } \\
\text { Night pain }\end{array}$ & & $\begin{array}{c}77(5.05) \\
40(2.6)\end{array}$ & $\begin{array}{c}181(12.25) \\
50(3.38)\end{array}$ & $\begin{array}{c}258(8.6) \\
90(3.0)\end{array}$ & $\begin{array}{l}0.000 \\
0.240\end{array}$ \\
\hline
\end{tabular}

\section{Peptic Ulcer Disease (PUD)}

As upper GI endoscopy was not done in the symptomatic subjects we could not definitely label one as patient with PUD. Among the persons having epigastric pain $25(0.8 \%$, male 14 , female 11 , $\mathrm{P}=0.690$ ) persons had pain persisting for more than 1 day and pain was relieved frequently by antacids. Among these subjects 10 were labelled as FD and the remaining 15 (male 8 , female $7, \mathrm{P}=1.00$ ) subjects could have PUD $(0.5 \%, \mathrm{P}=0.000)$. These 25 persons had no nocturnal pain and 6 patients (4 with FD) gave history of vomiting.
Functional dyspepsia

Among the study subjects 1919 (64\%) had recurrent dyspeptic symptoms. Among them 249 (8.3\%) patients fulfilled the criteria for FD according to Rome III criteria. FD was more prevalent in old age, in poor $(12.96 \%)$ and illiterate persons $(12.98 \%)$, in farmers $(10.52 \%)$ and day labourers $(10.97 \%)$ (Table I). Coexisting PDS-EPS was the most prevalent (57.8\%) subtype. PDS-EPS and PDS subgroups were more prevalent in women (Table III) while EPS subgroup was significantly more in men $(\mathrm{P}=0.004)$. There was no significant difference in the main dyspeptic symptom pattern in male and female. 
Approximately $40.56 \%$ dyspeptic patients had overlapping GERD symptoms.

\section{Upper abdominal bloating}

In the past 3 months $1265(42.16 \%)$ subjects had bloating and in $860(28.67 \%)$ it was for more than 6 months. Among these, 55 were classified as functional bloating (FB) $(\mathrm{M}: \mathrm{F}=1: 1.037, \mathrm{P}=$ 0.892 ) according to Rome III criteria, after excluding FD, IBS and functional constipation. Age, economic condition and education level were not found to affect prevalence of bloating. Upper abdominal bloating was more common in housewives (Table I). In patients with upper abdominal bloating, 3 (5.45\%) had night pain, 5 $(9.09 \%)$ had right upper quadrant pain, $3(5.45 \%)$ had weekly epigastric pain. Heart-burn $(34.45 \%$ vs $9.1 \%, \mathrm{P}=0.000)$ and early satiety $(30.9 \%$ vs $12.53 \%, \mathrm{P}=0.000$ ) was significantly more in $\mathrm{FB}$ patients in comparison to subjects without FB.

Functional gallbladder/sphincter of Oddi disorder Only two female subjects with upper abdominal pain fulfilled the criteria for functional gallbladder or sphincter of Oddi dysfunction or functional pancreatic disease according to Rome III criteria. But in the absence of objective evidence of enzyme levels we cannot comment whether they had functional or organic disorders. One of these two women also overlapped with FD.

\section{Reflux symptoms}

Distribution of heart-burn, chest pain and vomiting is shown in Table II. Chest pain occurring weekly was observed in 349 subjects $(\mathrm{M}: \mathrm{F}=1: 1.102, \mathrm{P}=0.210)$ and among these 212 (60.74\%) had weekly heart-burn and 97 (27.8\%) had FD. A total of $258(8.6 \%)$ subjects had vomiting, among these $19(7.4 \%)$ had weekly heart-burn, $6(2.3 \%)$ had upper abdominal bloating, $45(17.44 \%)$ had FD and $2(0.8 \%)$ patients had epigastric pain consistent with PUD (uninvestigated).

GERD: A total of 288 had weekly heart-burn (M:F=1:1.4, $\mathrm{P}=0.001)$; excluding dyspepsia cases $(\mathrm{n}=101), 187(6.2 \%)$ have been labelled as GERD. The prevalence of reflux disease was found to increase with increasing age. GERD was found more in female (7.1\%) (Table IV), in illiterate $(8.15 \%)$ and post-graduate subjects $(10.0 \%)$ and in upper class $(7.3 \%)$ (Table I). There was no significant difference in the mean age and symptom pattern among male and female subjects with GERD (Table IV). Approximately $35 \%$ patients with heart-burn had overlapping symptoms of FD. Table V shows demography and symptom pattern of patients with upper abdominal bloating.

Table III: Demography, symptom characters and subtypes of functional dyspepsia

\begin{tabular}{|l|c|c|c|}
\hline Variables & $\begin{array}{c}\text { Male } \\
\text { Number (\%) }\end{array}$ & $\begin{array}{c}\text { Female } \\
\text { Number (\%) }\end{array}$ & P value \\
\hline Prevalence & $123(8.1)$ & $126(8.6)$ & 0.691 \\
Mean age (years) & $42.37 \pm 18.41$ & $39.83 \pm 17.25$ & 0.264 \\
& & & \\
Symptoms of FD & & & \\
Postprandial fullness & $47(38.2)$ & $51(55.84)$ & 0.407 \\
Early satiation & $77(62.6)$ & $84(66.7)$ & 0.295 \\
Epigastric pain & $79(64.2)$ & $89(70.6)$ & 0.173 \\
Epigastric burning & $48(39.02)$ & $64(50.79)$ & 0.082 \\
Chest Pain & $34(27.64)$ & $63(50.0)$ & 0.000 \\
Heart-burn & $38(30.9)$ & $63(50.0)$ & 0.003 \\
Vomiting & $19(15.45)$ & $26(20.63)$ & 0.325 \\
FD subtypes & & & \\
PDS & $32(26.0)$ & $25(20.3)$ & $66(53.7)$ \\
EPS & $38(30.2)$ & $10(7.9)$ & $78(61.9)$ \\
PDS EPS & 0.484 & 0.006 & 0.201
\end{tabular}

Table IV: Demography and symptom pattern of reflux disease subjects

\begin{tabular}{|c|c|c|c|}
\hline Variables & $\begin{array}{c}\text { Male } \\
\text { Number (\%) }\end{array}$ & $\begin{array}{c}\text { Female } \\
\text { Number (\%) }\end{array}$ & $P$ value \\
\hline Prevalence & $82(5.4)$ & $105(7.1)$ & 0.059 \\
\hline Mean age (years) & $36.30 \pm 16.80$ & $37.05 \pm 16.47$ & 0.793 \\
\hline \multicolumn{4}{|l|}{ Symptoms of RD } \\
\hline Post prandial fullness & $25(30.48)$ & $23(21.90)$ & 0.237 \\
\hline Early satiation & $25(30.48)$ & $23(21.90)$ & 0.237 \\
\hline Epigastric pain & $25(30.48)$ & $37(35.24)$ & 0.534 \\
\hline Upper abdominal pain & $35(42.68)$ & $49(46.66)$ & 0.657 \\
\hline Chest pain & $52(63.41)$ & $74(70.47)$ & 0.347 \\
\hline Vomiting & $2(2.44)$ & $17(16.19)$ & 0.003 \\
\hline
\end{tabular}


Table V: Demography and symptom pattern of patients with upper abdominal bloating

\begin{tabular}{|l|c|c|c|}
\hline Variables & $\begin{array}{c}\text { Male } \\
\text { Number (\%) }\end{array}$ & $\begin{array}{c}\text { Female } \\
\text { Number (\%) }\end{array}$ & P value \\
\hline Prevalence & $27(1.8)$ & $28(1.93)$ & 0.892 \\
Mean age (years) & $40.63 \pm 18.41$ & $32.57 \pm 14.85$ & 0.050 \\
Symptoms & & & \\
\hline Early satiation (weekly) & $9(33.3)$ & $8(28.57)$ & 0.775 \\
Epigastric pain & $10(37.04)$ & $10(35.71)$ & 1.00 \\
Upper abdominal pain & $14(51.85)$ & $12(42.86)$ & 0.593 \\
Chest pain (weekly) & $9(33.3)$ & $9(32.14)$ & 1.00 \\
Heart-burn (weekly) & $10(37.04)$ & $9(32.14)$ & 0.781 \\
Vomiting & $2(7.4)$ & $4(14.29)$ & 0.669 \\
\hline
\end{tabular}

\section{Discussion}

Upper GI symptoms are common among general population and proved to be costly in terms of healthcare related expenditure and work lost. ${ }^{11}$ Majority of upper GI symptoms are functional in origin. 2,3,5,11-13 In Bangladesh we have limited data on the disease burden to our limited health care resources related to upper GI symptoms. The data of present survey confirmed that the different upper GI symptoms are prevalent in our general population.

It is evident from the result of the present study that around $75.8 \%$ of our general population was suffering from one of the upper GI symptoms, $69.1 \%$ had 2 or more symptoms and $56.8 \%$ had 3 or more upper GI symptoms. In total $38.9 \%$ had upper GI symptoms occurring weekly. In these subjects 249 (21.3\%) had functional dyspepsia according to Rome III criteria, $187(16.1 \%)$ had reflux disease, 55 $(4.71 \%)$ had functional upper abdominal bloating and 15 $(1.3 \%)$ were supposed to have PUD. In the study conducted by Talley et al $91 \%$ of the sample reported to have one or more GI symptoms while $81 \%$ had two or more symptoms. ${ }^{33}$ In a Dutch study, $88.8 \%$ of patients had one upper GI symptom, $10.1 \%$ had two and $1.1 \%$ had three or more upper GI symptoms (range 1-5; median 1) ${ }^{11}$. Another study in Canada reported that $51.4 \%$ had at least one upper GI symptoms in the prior three months. ${ }^{22}$

Functional dyspepsia prevalence in this study is comparable to other Asian countries but lower than that of Western countries. 3,4,8,11-15,19,20 Approximately 8-30\% and $8-23 \%$ of Asian people suffer from uninvestigated dyspepsia and FD respectively. ${ }^{1,3,12,13}$ Reflux symptoms were also found less prevalent in our community than western countries. ${ }^{7,17,18,24-29}$ Diana et $\mathrm{al}^{5}$ reported that the prevalence of dyspeptic, gastroesophageal, and dyspeptic and/or gastroesophageal symptoms were $16.3 \%$ (95\% CI
9.1-25.1\%), 24.2\% (95\% CI $18.2-30.5 \%)$ and $35.2 \%(95 \%$ CI $14.9-58.9 \%)$ respectively in the US population. The prevalence of GERD was found greater in studies with longer recall period. ${ }^{5}$

In a survey conducted in 1980, the reported point prevalence of PUD in the community was $15.0 \% .34$ The point prevalence rates of duodenal ulcer (DU) and gastric ulcer were $11.98 \%$ and $3.5 \%$ respectively in a study conducted by Azad et $\mathrm{al}^{35}$ in a rural community. A recent report on endoscopic evaluation of 532 patients with dyspepsia showed normal findings in $82.8 \%$ cases, DU in $10.35 \%$ cases and gastric erosion in $3.32 \%$ cases. ${ }^{36}$ We were not able to include investigations in our study. So we could not comment on prevalence of PUD. But when dyspepsia, GERD and other disorders were excluded, a total of $15(0.5 \%)$ patients with upper abdominal pain were suspected to have PUD. This data is consistent with an Asian study by Trimble et al. ${ }^{37}$ In the US studies, prevalence of PUD varied from 2.2 to $4.2 \%$ with a pooled prevalence of $3.3 \%(95 \%$, CI $2.2-4.2 \%){ }^{5}$ PUD prevalence was found to increase with increasing age, female sex and increased BMI and in Caucasians and tobacco users. ${ }^{1,5}$

One finding in our study is that the symptom prevalence was increased with short recall period ( 3 months) and the prevalence decreased dramatically when recall period is long $(>6$ months). It may be due to inability of the general population to remember less unpleasant events occurring long ago. Alternatively it may be due to short-persistence of minimal symptoms bothering the subjects less to draw their attention. Nevertheless, upper GI symptoms are common among our general population. Heart-burn $(1354,45.13 \%)$ and early satiation $(1347,44.9 \%)$ were the two most prevalent symptoms. A systematic review $^{5}$ reported that the prevalence of dyspeptic symptoms was more in studies with longer symptom recall periods $(22.8 \%$ vs $5.8 \%$ for shorter periods, $\mathrm{P}<0.001$ ), when samples were drawn from regional population $(23.2 \%$ vs $5.8 \%$ for national sample, $\mathrm{P}<0.001)$ and studies using validated questionnaire $(20.7 \%$ vs $4.7 \%$ for nonvalidated questionnaire, $\mathrm{P}=0.05$ ). 
In our study symptom prevalence decreased as the number and frequency of symptoms increased (one of the upper GI symptoms occurred monthly in 1938 subjects versus weekly in 1090 subjects). From the result of the present series we can conclude that symptom prevalence varies with frequency, duration and number of symptoms. Systematic reviews on studies of GI symptoms also reported that symptom prevalence rates varied with number and duration of symptoms. ${ }^{5,33}$ But contrary to our findings, previous studies have shown that longer symptom recall periods resulted in higher prevalence rates. ${ }^{5}$

Considerable overlap between dyspepsia and GERD is a consistent finding. In our study $40.56 \%$ dyspeptic patients had overlapping GERD symptoms and $35.06 \%$ patients with heart-burn had FD. By factor analysis Talley et $\mathrm{al}^{33}$ showed that natural groupings of upper GI symptoms can be identified such as dyspepsia, gastro-oesophageal reflux and a distinct grouping of bloating with visible distension and these groupings are clinically meaningful. They commented that subjects suffering from specific cluster using Rome criteria generally scored high on the appropriate symptom grouping and scored low on the other symptom group. On the other hand Agreus found no symptom groupings using factor analysis in Swedish population. ${ }^{38}$ Because of significant degree of symptom overlapping among FD, IBS and GERD, investigators suggested that patients with overlapping disorders have an irritable gut $^{37}$ and common and shared pathophysiologic mechanism is responsible for overlapping symptoms. ${ }^{39}$ Our data support that multiple upper GI disorders do exist in the general population.

In conclusion, upper GI symptoms are prevalent in our community and mostly functional in origin. Multiple disorders exist simultaneously in the community. Most prevalent symptom is heart-burn and overlapping symptoms are common in subjects having upper GI symptoms.

We had a number of limitations in our study. The questionnaire we used included only common upper GI symptoms, not all symptoms. Laboratory or endoscopic evaluation of the subjects was not feasible in our setting. It may cause overestimation of functional upper GI disorders. Strength of our study is that it is a population-based study and likely to reflect the true prevalence of upper GI symptoms.
We hope that our data will provide background information and will stimulate others for further studies.

\section{Acknowledgement}

We thank Incepta Pharmceuticals Ltd. and Beximco Pharma Ltd. of Bangladesh who partly financed this study. We also thank Department of Statistics, Shahjalal University of Science and Technology, Sylhet, Bangladesh for their active co-operation in analysing the data.

\section{References}

1. Mahadeva S, Goh KL. Epidemiology of functional dyspepsia: a global perspective. World J Gastroenterol 2006; 12: 2661-2666. [PubMed]

2. Ghoshal UC, Singh R, Chang FY, Hou X, Wong BCY, Kachintorn U. Epidemiology of uninvestigated and functional dyspepsia in Asia: facts and fiction. J Neurogastroenterol Motil 2011; 17: 235-244. [PMC free article] [PubMed]

3. El-Serag HB, Talley NJ. Systematic review: the prevalence and clinical course of functional dyspepsia. Aliment Pharmacol Ther 2004; 19: 643-654. doi: 10.1111/j.13652036.2004.01897.x. [PubMed] [Cross Ref]

4. Heading RC. Prevalence of upper gastrointestinal symptoms in the general population: a systematic review. Scand J Gastroenterol Suppl. 1999; 231: 3-8.

5. Sobieraj DM, Coleman SM, Coleman CI. US prevalence of upper gastrointestinal symptom: a systematic literature review. Am J Manag Care 2011; 17(11): e449-e458.

6. Hycox A, Einarson T, Eggleston A. The health economic impact of upper gastrointestinal symptoms in the general population: results from Domestic/International Gastroenterology Surveillance Study (DIGEST). Scand J Gastroenterol Suppl. 1999; 231: 38-47.

7. Locke GR, Talley NJ, Fett SL, Zinsmeister AR, Melton LJ $3^{\text {rd }}$. Prevalence and clinical spectrum of gastroesophageal reflux: a population based study in Omsted County, Minnesota. Gastroenterology 1997; 112(5): 1428-1456.

8. Talley NJ, Boyce P, Jones M. Dyspepsia and health care seeking in a community: how important are psychological factors? Dig Dis Sci 1998; 43: 1016-1022.

9. Talley NJ. Quality of life in functional dyspepsia. Scand J Gastroenterol Suppl. 1996; 221: 21-22

10. Miwa H, Ghoshal UC, Gonlachanvit S, Gwee K, Ang T, Chang $\mathrm{F}$ et al. Asian Consensus Report on Functional Dyspepsia. J Neurogastroenterol Motil 2012; 18(2): 150-168. 
11. Bröker LE, Hurenkamp GJB, ter Riet G, Schellevis FG, Grundmeijer HG, van Weert HC. Upper gastrointestinal symptoms, psychosocial co-morbidity and health care seeking in general practice: population based case control study. BMC Fam Pract 2009; 10: 63.

12. Kwan AC, Bao TN, Chakkaphak S, Chang FY, Ke M, Law NM et al. Validation of Rome II criteria for functional gastrointestinal disorders by factor analysis of symptoms in Asian patient sample. J Gastroenterol Hepatol 2003; 18: 796-802. [PubMed]

13. Wai CT, Yeoh KG, Ho KY, Kang JY, Lim SG. Diagnostic yield of upper endoscopy in Asian patients presenting with dyspepsia. Gastrointest Endosc 2002; 56: 548-551. [PubMed]

14. Chua AS. Reassessment of functional dyspepsia: a topic review. World J Gastroenterol 2006; 12: 2656-2659. [PubMed]

15. Saad RJ, Chey WD. Review article: current and emerging therapies for functional dyspepsia. Aliment Pharmacol Ther 2006; 24: 475-492. doi: 10.1111/j.13652036.2006.03005.x. [PubMed] [Cross Ref]

16. Manabe N, Haruma K, Hata J, Imamura H, Kamada T, Kusunoki $\mathrm{H}$ et al. Clinical characteristics of Japanese dyspeptic patients: is the Rome III classification applicable? Scand J Gastroenterol 2010; 45: 567-572. [PubMed])

17. Kahrila PJ, Pandoltino JE. Gastroesophageal reflux disease and its complications, including Barrett's metaplasia. In: Feldman M, Friedman LS, Sleisenger MH (eds). Sleisinger and Fordtan's gastrointestinal and liver disease: pathophysiology, diagnosis, management. $7^{\text {th }}$ edn. Atlanta: Elsvier Science (USA), 2002: 640-663.

18. Klauser AG, Schindlbeck NE, Muuler-Listner SA. Symptoms in gastroesophageal reflux disease. Lancet 1990; 335: 205-208.

19. Talley NJ, Meineche-Schmidt V, Pare P, Duckworth, Raisanen, Pap et al. Efficacy of omeprazole in functional dyspepsia: double-blind, randomized, placebo-controlled trials (the Bond and Opera studies). Aliment Pharmacol Ther 1998; 12: 1055-1065. [PubMed]

20. Moayyedi P, Soo S, Deeks J, Delaney B, Innes M, Forman D. Pharmacological interventions for non-ulcer dyspepsia (Cochrane review). In: The Cochrane Database Syst Rev 2006; Issue 4. CD001960. [PubMed]

21. Talley NJ, Fung LH, Gilligan IJ, McNeil D, Piper DW. Association of anxiety, neuroticism, and depression with dyspepsia of unknown cause. A case-control study. Gastroenterology 1986; 90: 886-892. [PubMed]

22. Tougas G, Chen Y, Hwang P, Liu MM, Eggleston A. Prevalence and impact of upper gastrointestinal symptoms in the Canadian population: findings from the DIGEST study. Domestic/International Gastroenterology Surveillance Study. Am J Gastroenterol. 1999; 94(10): 2845-2854.

23. Talley NJ, Stanghellini V, Heading RC, Koch KL, Malageleda JR, Tytgat GN. Functional gastroduodenal disorders. Gut 1999; 45(Suppl 2): 1137-1142.

24. Wiklund I, Talley NJ. Update on health-related quality of life in patients with gastroesophageal reflux disease. Expert Rev Pharmacoeconomics Outcomes Res 2003; 3: 341-350.

25. Khosbaten M. Gastroesophageal reflux disease in Northwestern Tabriz, Iran. Indian J Gastroenterol 2003; 22: $138-139$.

26. Wong WM, Lai KC, Lam KFK, Hui WM, Hu WH, Lam CLK et al. Prevalence, clinical spectrum and health care utilization of gastroesophageal disease in a Chinese population: a population-based study. Aliment Pharmacol Ther 2003; 18: 595-604.

27. Shaha M, Perveen I, Alamgir MJ, Masud MH, Rahman $\mathrm{MH}$. Prevalence and risk factors for gastro-esophageal reflux disease in a the North-Eastern part of Bangladesh. Bangladesh Med Res Counc Bul 2012; 38: 108-113.

28. Wang A, Liao X, Xiong L, Peng S, Xiao Y, Liu S et al. The clinical overlap between functional dyspepsia and irritable bowel syndrome based on Rome III criteria. BMC Gastroenterol 2008; 8: 43. [PMC free article] [PubMed]

29. Kim JS, Lee KJ, Kim JH, Hahm KB, Cho SW. Functional gastrointestinal disorders in patients referred to specialist gastroenterologists in a tertiary hospital. Korean J Neurogastroenterol Motil 2004; 10: 111-117.

30. Kitapcioolu G, Mandiracioðlu A, Caymaz Bor C, Bor S. Overlap of symptoms of dyspepsia and gastroesophageal reflux in the community. Turk J Gastroenterol 2007; 18: 14-19. [PubMed]

31. Lee SY, Lee KJ, Kim SJ, Cho SW. Prevalence and risk factors for overlaps between gastroesophageal reflux disease, dyspepsia, and irritable bowel syndrome: a population-based study. Digestion 2009; 79: 196-201. [PubMed]

32. Drossman DA, Corazziari E, Delvaux M, Spiller RC, Talley NJ, Thompson WG et al. In: Drossman DA, Corazziari E, Delvaux M, Spiller RC, Talley NJ, Thompson WG, Whitehead WE (eds). The functional gastrointestinal disorders. $3^{\text {rd }}$ edn. Virginia: Degnon Associates, Inc., McLean, 2006: 963-990.

33. Talley NJ, Boyce P, Jones M. Identification of distinct upper and lower gastrointestinal symptoms in an urban population. Gut 1998; 42: 690-695. 
34. Hasan M, Ali SMK, Azad Khan AK. Peptic ulcer disease in Bangladesh - an endoscopy survey. Gut 1985; 16: A. 1117.

35. Azad Khan AK, Hasan M, Roy PK, Aziz S, Khan MH, Ali SMK et al. Peptic ulcer in Bangladesh. Bangladesh Med Res Counc Bul 1987; 13: 29-42.

36. Shafiullah ABM, Bhuiyan MMR, Masud H, Roy PK. Endoscopic findings in a district private hospital of Bangladesh. Bangladesh J Medicine 2009; 20: 17-19.

37. Trimble KC, Farouk R, Pryde A, Douglas S, Heading RC. Heightened visceral sensation in functional gastrointestinal disease is not site-specific. Evidence for a generalized disorder of gut sensitivity. Dig Dis Sci 1995; 40: 1607-1613.
38. Agreus L, Borgquist L. The cost of gastro-oesophageal reflux disease, dyspepsia and peptic ulcer disease in Sweden. Pharmacoeconomics 2002; 20: 347-355. doi: 10.2165/00019053-200220050-00006.[PubMed] [Cross Ref]

39. Corsetti M, Caenepeel P, Fischler B, Janseens J, Tack J. Impact of coexisting irritable bowel syndrome on symptoms and pathophysiological mechanisms in functional dyspepsia. Am J Gastroenterol 2004; 99:1152-1159. doi: 10.1111/j.1572-0241.2004.30040.X. [PubMed] 